\title{
Development of Serum Bactericidal Assay for P. aeruginosa
}

\author{
Dr. Ramya Anandan, Nandhini D \\ Dr. MGR Janakicollege of arts and science for women, Chennai, Tamilnadu
}

\begin{abstract}
The primary objective of this research work is to develop a serum bactericidal assay (SBA) for the quantification of bactericidal antibodies in human serum for P.aeruginosa (pSBA). Whole cell antigens (Heat and formalin inactivated) were generated from clinical isolates. It was screened for Anti-pseudomonas antibodies (IgG) using ELISA technique. An increased sero-reactivity with heat killed preparation 54-63\% were observed than formalin killed. It may be due to the presence of different epitopes in heat\& formalin inactivated antigen. ELISA positive sera were pSBA positive. No sero-cross reactivity in pSBA. No major variations in pSBAtitre with different bacterial inoculum tested. pSBA antibody driven with no interference with endogenous complement. This study demonstrated Anti-pseudomonas functional activity in human serum.
\end{abstract}

Keywords: Serum bactericidal assay, P.aeruginosa, Whole cell antigen, ELISA, endogenous complement, Functional antibody

\section{Introduction}

Pseudomonas is the most important genus in the order Pseudomonadales, the family Pseudomonaceae. Pseudomonas aeruginosa is a ubiquitous and remarkably versatile bacterium (Tidy, 2014). These bacteria are straight or slightly curved rods, $0.5-1.0 \square$ mby $1.5-5.0 \square$ min size and are motile by one or several polar flagella. Mucoid form (capsule) is an adaptation mechanism of $P$. aeruginosa for surviving in aquatic environments by forming a polysaccharide net/biofilm rich in alginate (Pedersen et al., 1990)

\subsection{Virulence Factors}

Pseudomonas has a number of virulence factors (Lyczak et al., 2000), which includes:

- Capsule, exotoxin A and various proteases that facilitated immune evasion, tissue and cellular damage for pathogenicity

- Pyocyanine - P. aeruginosa synthesizes a characteristic blue redox-active secondary metabolite, that is chloroform-soluble and a member of the tricyclic compounds "phenazine" called pyocyanine which is chemically, hydroxy5-methyl-phenazine (van delden 2004)

\subsection{Epidemiology}

$P$. aeruginosa flourishes in different ecological environments including soil, river, waste water, plant, animal and human. This Gram-negative bacteria lives in water and soil and acts as an opportunistic pathogen in humans and plants (Jamileh et al., 2012). Many advances in understanding the physiology and biochemistry of this organism and microbes in general have been borne off these studies. The genome of $P$. aeruginosa has an unusually large number of genes for catabolism, nutrient transport, the efflux of organic molecules, and metabolic regulation. This may explain its ability to grow in many environments and resist antibiotics (Arancibia et al., 2002).

\subsection{In vitro Serology}

The serum bactericidal test (SBT) is a modification of the broth dilution method that measures the bactericidal activity of the patient's serum during antimicrobial therapy against the bacterial pathogen isolated from that patient. It is one of the few in vitro tests performed in the clinical microbiology laboratory that incorporates the interaction of the pathogen, the antimicrobial agent, and the patient. Although the use of such a test for assessing the bactericidal activity in a patient's serum has been widely used for 40 years, its performance, results, and interpretation have been subject to question and controversy. The bactericidal effect of normal serum on gram-negative bacteria was investigated with the objective of determining whether this antibody-complement reaction could be used for the measurement of antibody. The major variables affecting the outcome of this complement dependent reaction were explored systematically to establish the test conditions in which specific antibody was the limiting factor(Stratton 1988).

\section{Review of Literature}

The aim of this study is to develop a serum bactericidal assay (SBA) to evaluate the ability of the serum antibodies to kill $\mathrm{P}$. aeruginosa by direct augmentation of complement cascade. On reviewing the literature, serum bactericidal assay model is popularly used as a platform to quantify the minimum Inhibitory concentration of antibiotics as SBT rather than SBA. Even though Gram negative bacterium owing to their cell complexity are predominantly killed by complement cascade and less through opsonophagocytosis, some strains of serum non-sensitive Pseudomonas strains tends to interfere with complement components. Hence, we found limited literatures pertaining to the development of SBA for pseudomonas.

\subsection{Historical review of the SBT}

Of the laboratory methods for assessing bactericidal activity, it is not surprising that the SBT has received the most attention. Tests to estimate the bactericidal activity of blood 


\section{International Journal of Science and Research (IJSR) \\ ISSN (Online): 2319-7064}

Index Copernicus Value (2015): 78.96 | Impact Factor (2015): 6.391

antedate the antimicrobial era. A logical extension of this concept is the estimation of the bactericidal activity of blood during the antimicrobial treatment of serious infections.

Although (Schlichter and MacLean, 1947) are generally given credit for the SBT, they tested only the inhibitory activity of serum and did not define criteria for the determination of bactericidal endpoints. In fact, it was (Fisher, 1952) who subsequently modified Schlichter's method by sub culturing the tubes that failed to exhibit macroscopic evidence of growth after overnight incubation. Although Fisher addressed the need for determining the serum bactericidal concentration, there have been no universally accepted criteria for micro dilution or macro dilution methods for performing bactericidal testing despite the use of the SBT for 40 years. It is no wonder that critical reviews of the SBT have not found this test clinically useful and have stressed the need for standardization of the methodology.

As the SBT is presently done, there are marked differences from laboratory to laboratory in every major variable in the test. Inadequate descriptions and variation in test methods among clinical laboratories preclude objective assessment of results from clinical studies. Therefore, the National Committee for Clinical Laboratory Standards has recently published proposed guidelines for both bactericidal testing and the SBT.

These guidelines review aspects of bactericidal testing and the SBT which require standardization. The use of these guidelines through the National Committee for Clinical Laboratory Standards consensus mechanism should allow agreement about standardized methods. This will then enable the appropriate prospective clinical trials to be done to provide a rational data base for clinical interpretive criteria for the SBT in serious infections (Stratton, 1988)

Bacterial survival in the host is accompanied by the acquisition of different immune-evasive strategies. These strategies involve alteration of the bacterial surface, such as production of a capsule or immune-modulating membrane proteins, or secretion of soluble immune-evasion proteins, such as proteolytic factors. P.aeruginosa secretes a number of toxins and virulence factors, like elastase and alkaline protease (AprA) (Alexander et al., 2012)

\subsection{Effect of serumonPseudomonas species:}

Pseudomonas enzymes, especially elastase and alkaline protease, were shown to have direct effect on the serum hemolytic complement as a whole, and on the two recognition molecules of complement, $\mathrm{C} 1 \mathrm{q}$ and $\mathrm{C} 3$ in particular(Alexander J. laarmen, et.al, 2012). Incubation of serum with $0-50 \mu \mathrm{g} / \mathrm{ml}$ elastase or protease $\left(60 \mathrm{~min}, 37^{\circ} \mathrm{C}\right)$ resulted in a dose-dependent depletion of hemolytic complement with the protease being 3-4 times more efficient than elastase.A combination of the siderophores produced by Pseudomonasaeruginosa, pyochelin and pyoverdin, dramatically stimulates the growth of this bacterium in medium containing human transferrin. The amount of growth stimulation observed when each siderophore was added alone was only slightly less than the amount observed with the combination. Siderophoredefective mutants of strain PAO1 were isolated to test the effects of siderophore production on growth in transferrin and human serum(R Ankenbauer, et.al., 1985)

\subsection{Effect of bacterial absorption on serum killing}

The rate of intracellular bacterial lysis is largely controlled by the lysozyme concentration but complement is also necessary. Killing is closely related to complement concentration. Antibody is needed in such small amounts that it is rarely a limiting factor (Taylor, 1983)

Both lysis and killing are stopped by bentonite absorption of serum and complete return to normal is not attained by subsequent addition of egg-white lysozyme. In a lysozymefree system lysis does occur after some delay probably due to the action of complement and antibody alone. In the presence of adequate complement and antibody the loss of complement (measured haemolytically) in bentonite treated serum is inadequate to account for the fall in bactericidal activity (Glynn and Milne, 1965).Optimal phagocytosis by PMNs required the presence of heat-stable antibody and heat labile opsonin; the activity of the latter was primarily due to the first four components of complement. Heat-stable opsonizing antibody was greatly augmented in sera of survivors of bacteremic infection. Normally functioning PMNs are essential to host defenses, since most invasive strains of P.aeruginosa are resistant to serum (Lowel and Young, 1972)

\subsection{Inhibitors of serum killing:}

Investigation has shown that the complement-dependent bactericidal activity of normal human serum towards certain organisms requires magnesium ion, and also a serum euglobulin, properdin, which is distinct from antibody and complement (Pillemer.et.al., 1954; Wardlaw and Pillemer, 1956). The requirement for properdin was demonstrated by the loss of bactericidal activity following absorption of serum with the yeast cell-wall fraction 'zymosan'. The conditions of absorption were controlled so that properd in was removed without loss of component C'3. Properdin itself was eluted from the zymosan residue, and was able to restore bactericidal activity to properdin-deficient serum. The requirement for $\mathrm{Mg}$ ion was similarly demonstrated by the decrease in bactericidal activity following treatment of the serum with the cation ex- change resin Amberlite IRC50 (sodium cycle). Addition of $\mathrm{MgC} 1$, restored bactericidal activity to resin-treated serum. The outer membrane constitutes the main barrier to the serum killing of gramnegative bacteria. Serum-resistant cells may be sensitized to the bactericidal action of serum by treatment with Tris and EDTA, a process known to lower the permeability barrier of the outer membrane by affecting the release of approximately half of the complexed lipopolysaccharide (It appears that serum resistance does not result from a block in the activation of the complement cascade. Rather, MACs formed on the surfaces of serum-resistant strains are not effectively inserted into the bacterial membranes and are released without causing lethal damage.

\section{Volume 6 Issue 7, July 2017 www.ijsr.net}




\section{International Journal of Science and Research (IJSR) \\ ISSN (Online): 2319-7064}

Index Copernicus Value (2015): 78.96 | Impact Factor (2015): 6.391

\subsection{Sequence of Pseudomonas cellular events after exposure to serum}

Exposure of susceptible gram-negative cells to serum is generally followed by a period during which there is little apparent change in viability; the length of this period varies depending on the bacterial strain used, the test system, the serum concentration, and the metabolic state of the bacterial cells (D.Rowley and A.C.Wardlaw, 1958).Integration of the MAC into phospholipids bilayer areas of the outer membrane therefore disrupts outer membrane integrity and removes the barrier to hydrolysis of peptidoglycan by lysozyme. It is unlikely; however, that damage confined to the outer membrane is responsible for the lethal activity of complement (Taylor, 1983)

\section{Complement Role}

In the late 19th century, Hans Ernst August Buchner found that blood serum contained a "factor" capable of killing bacteria. In 1894, Richard Pfeiffer, a German scientist, had discovered that when cholera bacteria were injected into the peritoneum of a guinea pig immunized against the infection, the pig would rapidly die. This bacteriolysis, Bordet discovered, did not occur when the bacteria was injected into a non-immunized guinea pig, but did so when the same animal received the antiserum from an immunized animal. Moreover, the bacteriolysis did not take place when the bacteria and the antiserum were mixed in a test tube unless fresh antiserum was used.

However, when Bordet heated the antiserum to 55 degrees centigrade, it lost its power to kill bacteria. Finding that he could restore the bacteriolytic power of the antiserum if he added a little fresh serum from a non immunized animal, Bordet concluded that the bacteria killing phenomenon was due to the combined action of two distinct substances, an antibody in the antiserum, which specifically acted against a particular kind of bacterium, and a non-specific substance, sensitive to heat, found in all animal serums, which Bordet called "alexine" (later named "complement").

The term "complement" was introduced by Paul Ehrlich in the late 1890s, according to him, the immune system consists of cells that have specific receptors on their surface to recognize antigens. Upon immunization with an antigen, more of these receptors are formed, and they are then shed from the cells to circulate in the blood. These receptors, which we now call "antibodies," were called by Ehrlich "amboceptors" to emphasize their bi-functional binding capacity: They recognize and bind to a specific antigen, but they also recognize and bind to the heat-labile antimicrobial component of fresh serum. Ehrlich, therefore, named this heat-labile component "complement," because it is something in the blood that "complements" the cells of the immune system.

There have been a number of studies which have examined the mechanism of serum killing of P.aeruginosa. Several investigators have presented evidence suggesting the importance of the classical complement pathway (CCP) activated by antibodies in the killing of some P.aeruginosa strains (Module Microbiology). Reports have stated that certain strains are killed by complement activated via the alternative complement pathway (ACP) in the apparent absence of antibodies, whereas others have suggested a role for both pathways. (Schiller 1987).

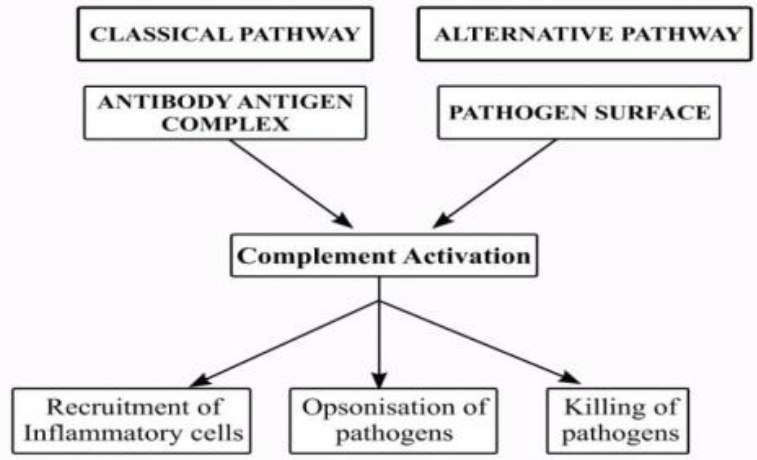

Flow Chart 1: Complement pathway

\begin{tabular}{|c|c|c|}
\hline Sample ID & Clinical samples & Location \\
\hline 1 & Blood & Mylapore \\
\hline 2 & Urine & Park town \\
\hline 3 & Swab & Royapettah \\
\hline 4 & Swab & Mylapore \\
\hline 5 & Swab & Adambakkam \\
\hline 6 & Blood & Velacherry \\
\hline 7 & Urine & Alwarpet \\
\hline
\end{tabular}

Resistance of P.aeruginosato killing by complement and evasion from neutrophils are major virulence traits that allow this organism to survive within the bloodstream and inflamedlung. To date, the actual mechanism for complement interaction on the P.aeruginosa surface is not well understood.(Module Microbiology)Comparatively little work has been done on the role of anti-capsular antibodies in the serum bactericidal reaction. Antibodies to the exopolysaccharide of mucoid strains of $P$. aeruginosa are known to activate complement in the bactericidal reaction (Taylor 1983)Over the past half century an extensive literature has accumulated on the bactericidal action in vitro of normal serum on gram-negative bacteria (Wilson and Miles, 1955; Skarnes and Watson, 1957).

\section{Methodology}

\subsection{Collection of sample:}

Samples collected from clinical laboratory, Hospitals totally 7 samples and transported in Stuart medium.

\subsection{Isolation of pathogen:}

The sample was serially diluted and plated onto nutrient agar plates, kept for incubation at $37^{\circ} \mathrm{C}$ for 24 hours.

\subsection{Characterization of the Pseudomonas clinical isolate}

A loopful of the inoculum from incubated nutrient agar plates was streaked on to selective media Pseudomonas isolation agar.Preliminary morphological and biochemical tests such as Gram staining, motility, Indole, Methyl red, Vogesproskauer, Citrate, Triple sugar iron, Urease, Nitrate reduction, Catalase and Oxidase were performed using

\section{Volume 6 Issue 7, July 2017 www.ijsr.net}




\section{International Journal of Science and Research (IJSR) \\ ISSN (Online): 2319-7064 \\ Index Copernicus Value (2015): 78.96 | Impact Factor (2015): 6.391}

standard methodology (Cappuccino, 1999) and results were tabulated.

\subsection{Collection of serum sample for serological tests}

The serum samples were collected from various hospitals and diagnostic laboratories in and around Chennai.

Serum samples were collected from laboratory through lab technicians and stored in eppendorff and kept in ice. Totally 22 multiple aliquots of serum were prepared.

\subsection{Elisa for anti Pseudomonas antibodies in human serum}

\subsubsection{P. aeruginosa antigen preparation for ELISA}

Human serum was screened for the presence of antipseudomonas antibodies using ELISA antibody capture technique. To capture the pseudomonas specific serum antibodies, two different whole cell antigenic preparations were made from three $P$. aeruginosa clinical isolates, Ps1, Ps2, Ps3.Protocol adopted for the generation of heat killed and formalin killed antigen to be used for antibody capture in ELISA is given in Flow Chart 2.

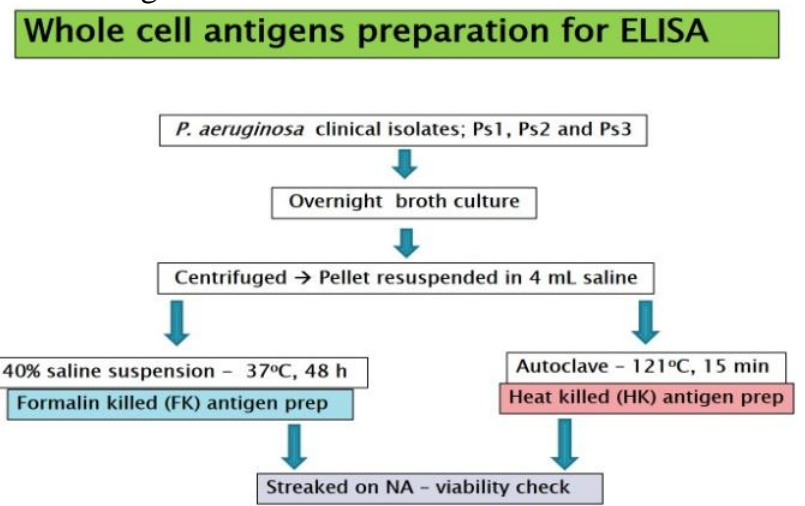

Flow Chart 2: $P$. aeruginosa antigen preparation for ELISA

\subsubsection{P. aeruginosa ELISA}

To screen a panel of human serum $(n=20)$ for pseudomonas specific antibody $(\operatorname{IgG})$, ELISA antibody capture technique was used with heat killed and formalin killed whole cell antigen preparations of 3 pseudomonas clinical isolate viz., Ps1, Ps2, Ps3. ELISA protocol is given in Flow Chart 3.

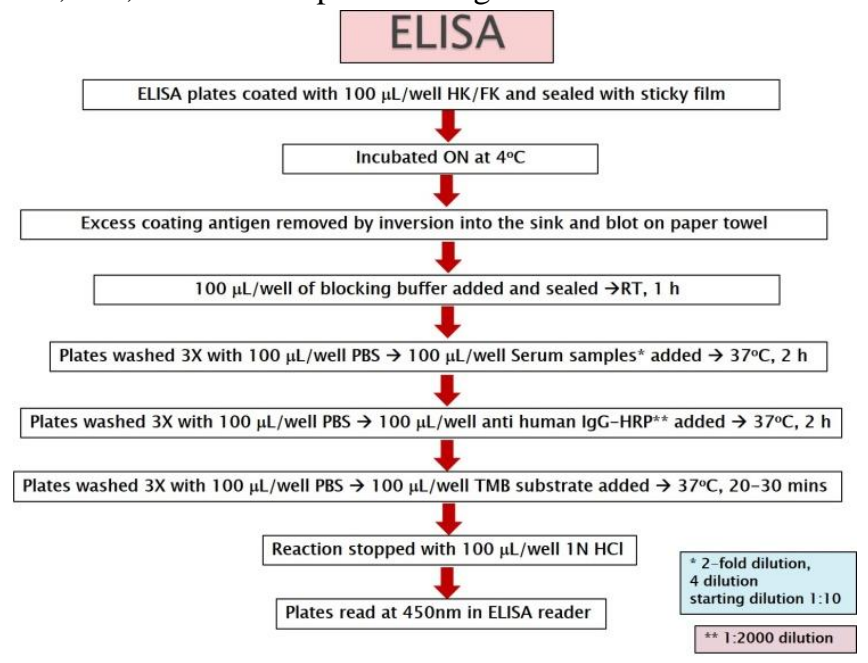

Flow Chart 3: P. aeruginosa ELISA
As there is no standard reference serum available to generate concentration vs $\mathrm{OD}_{450}$ calibration curve, OD450 for each serum sample was used for comparative analysis. In order to normalize the impact of dilution on the overall antibody concentration in various serum samples, OD450 was converted and expressed as weighted average (WA) using the following formula:

$\mathrm{WA}=\Sigma(\mathbf{a} 1 \times \mathbf{d} 1, \mathbf{a} 2 \times \mathbf{d} 2 \ldots \mathbf{a n} \times \mathbf{d n}) / \Sigma(\mathbf{d} 1, \mathbf{d} 2 \ldots \mathrm{dn})$

$W A=$ Weighted average; $a l=O D_{450}$ for first dilution; $d 1=$ dilution factor; $\Sigma=$ Sum

\subsection{Pseudomonas serum bactericidal assay}

Serum bactericidal assay for pseudomonas was developed as described in the flow chart 4. Based on the ELISA observations, only two P. aeruginosa strains, Ps1 and Ps3 were tested for serum bactericidal activity against two positive and two negative human sera.

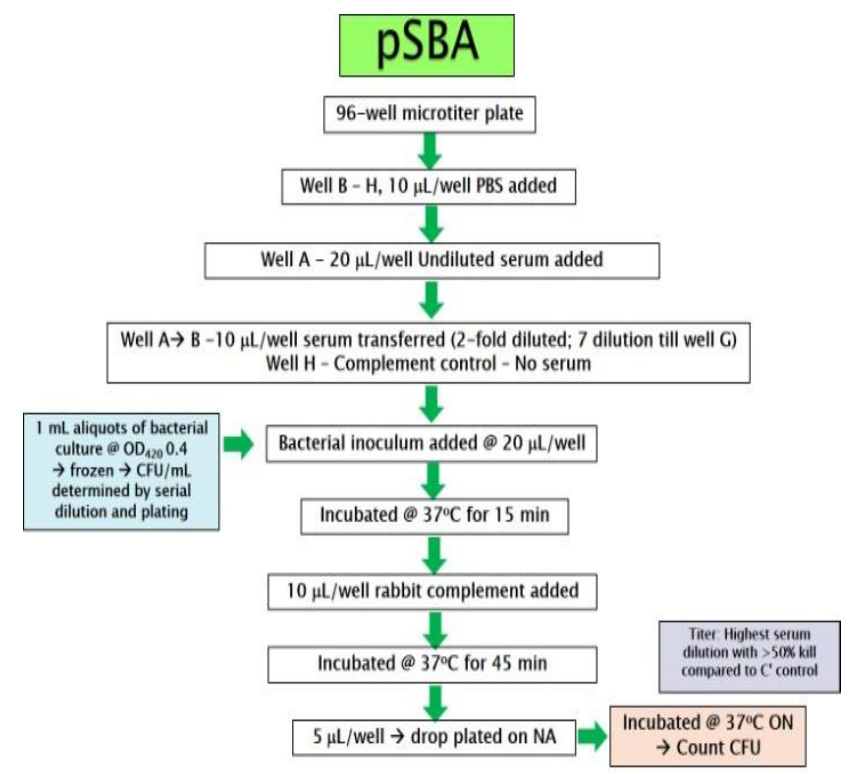

Flow Chart 4: $P$. aeruginosaSBA

Two important assay variables were included for optimization. The first variable is the target antibody ratio. While serum samples were diluted 2-fold from undiluted samples through 7 dilutions, the bacterial target was inoculated in 4 different counts, 50, 60, 70 and $80 \mathrm{CFU} /$ well. The second important variable is the endogenous complement source that may contribute to the background killing of the target bacterium. This question was addressed by including a heat inactivated $\left(56^{\circ} \mathrm{C}\right.$ for $30 \mathrm{~min}$ in a water bath) positive serum control. Inclusion of complement control served two purposes. While the complement control along with negative control gave as data to set the baseline (50\% killing), it also enabled us monitor the target bacterium for direct complement inactivation in which case we would observe a flat line in killing with no serum dilution dependent variation in killing in comparison to $C^{\prime}$ control. 


\section{International Journal of Science and Research (IJSR) \\ ISSN (Online): 2319-7064}

Index Copernicus Value (2015): 78.96 | Impact Factor (2015): 6.391

\section{Result}

Table 1

\begin{tabular}{|c|c|}
\hline Isolates & Sample ID \\
\hline Ps1 & 6 \\
\hline Ps2 & 3 \\
\hline Ps3 & 2 \\
\hline
\end{tabular}
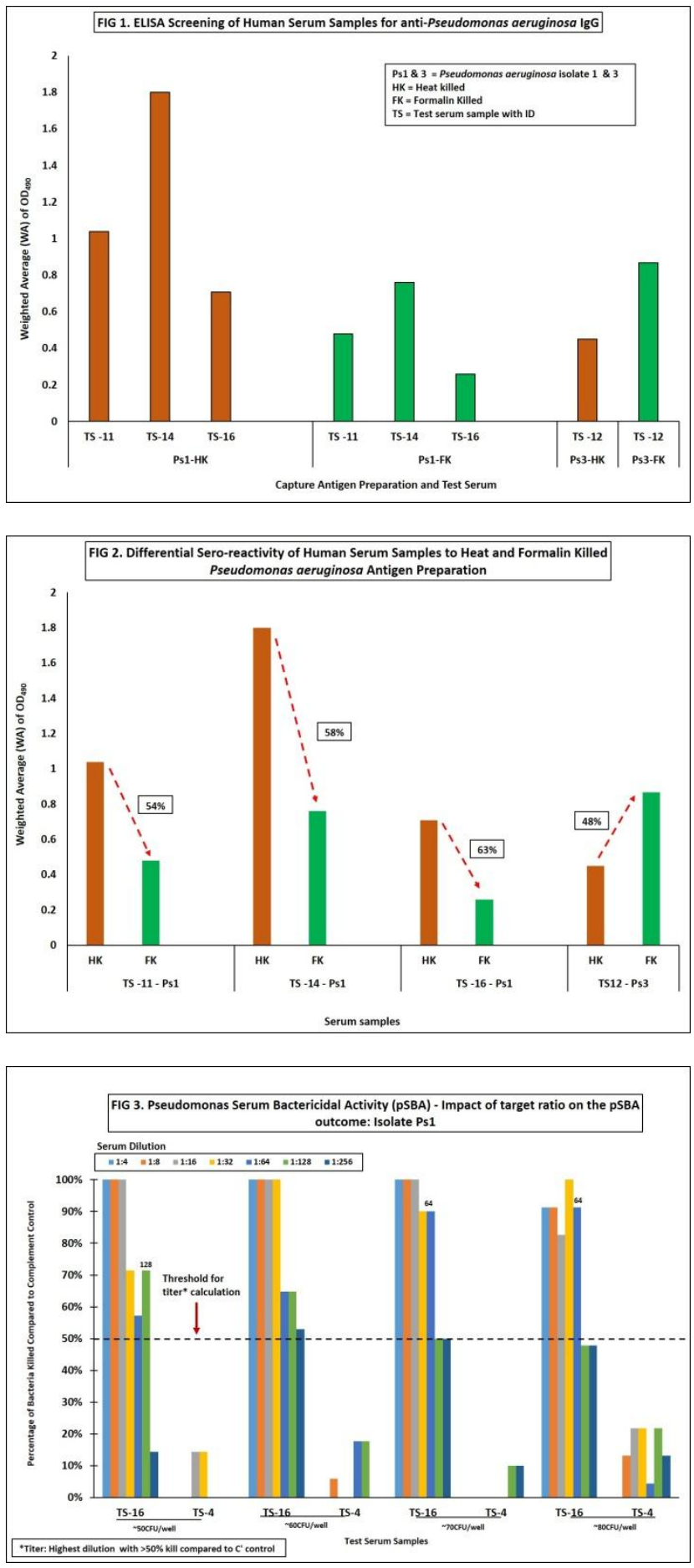
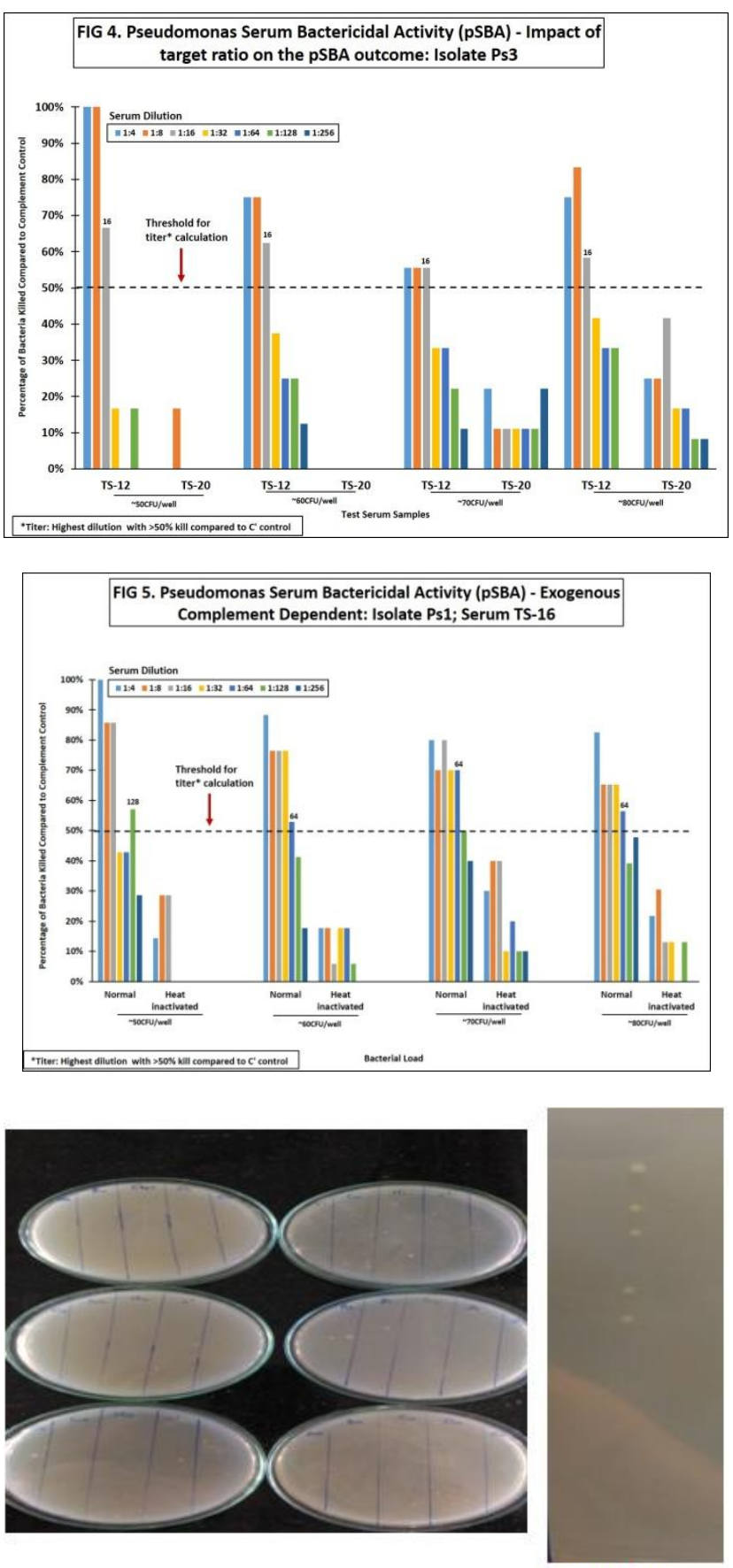

\section{Discussion}

C' control

The colonies from the nutrient agar plates were confirmed as Pseudomonas aeruginosa by selective media platting (Plate 1 - 3) and biochemical tests (Table 1).

Three Pseudomonas aeruginosa clinical isolates (Ps1, Ps2 and Ps3) were selected for antigen preparation. Heat and formalin killed antigen preparations were generated from these Pseudomonas isolates as described in the methodology. These whole cell antigen preparations were coated in the ELISA plate as capture antigens. Human sera $(n=20)$ obtained from a clinical laboratory were screened for anti-pseudomonas antibodies (IgG) using these ELISA plates. Among the 20 test serum samples, three (TS-11, TS14 and TS-16) were found to be reactive with both heat and formalin killed preparations of Ps1 (FIG 1). Human serum sample TS-12 was reactive with the antigenic preparations

\section{Volume 6 Issue 7, July 2017}




\section{International Journal of Science and Research (IJSR) \\ ISSN (Online): 2319-7064}

Index Copernicus Value (2015): 78.96 | Impact Factor (2015): 6.391

(both heat and formalin killed) of Ps3. None of the test serum samples reacted with Ps2 antigenic preparations. For Ps1, serum sample TS-14 exhibited maximum serareactivity in both heat and formalin killed preparations (Weighted Average (WA) of $\mathrm{OD}_{490}=1.8$ and 0.8 respectively) followed by $\mathrm{TS}-11$ (WA $=1.0$ and 0.5 respectively).

Data presented in FIG 2, reveals a clear difference in serareactivity of test serum between heat and formalin killed preparation. For Ps1, all three positive serum samples demonstrated an increase in sera-reactivity with heat killed preparations compared to formalin killed $(54-63 \%)$. On the other hand, TS-12 the only serum sample with sole reactivity with Ps3 whole cell antigenic preparations, exhibited a $48 \%$ reduction in reactivity with heat killed preparation compared to formalin killed preparations. Is this difference in reactivity, 1) contributed by a simple changes in the epitope densities due to different treatments of the bacterial cell (heat and formalin); 2) Or does different inactivation procedures resulting in the exposure of different epitope that were captured by the polyclonal human serum; 3) Or is this due to changes in the conformation of the epitopes in response to heat or formalin that impacts the affinity kinetics $(\mathrm{Km})$ of the antibodies in the human serum? Some of these questions will be addressed in future with additional experiments. This includes, homologous and heterologous competition experiments, and antibody avidity analysis

The primary objective of this research work is to develop a serum bactericidal assay (SBA) for the quantification of bactericidal antibodies in human serum for $P$. aeruginosa (pSBA). One of the critical variables in pSBA is the target (bacterial) ratio in the reaction. Hence, the bacterial inoculum was optimized according to the method described in the previous section with a positive and negative serum and the results presented in FIG 3 - 4). With the pSBA titer threshold set at $50 \%$ bacterial kill compared to complement control (without serum), the positive control reported a pSBA titer of 64-128 at 4 different inoculum load ( 50, 60, 70 , and $80 \mathrm{CFU} /$ well) of Ps1. Similarly for Ps3, the positive control has returned a pSBA titer of 16 in all 4 inoculum load (FIG 4).

Human serum contains endogenous complement that may contribute some background killing of the bacterium included in the assay mixture. This may not adversely affect the outcome of the assay as the serum gets diluted resulting in the endogenous complement also even if present. Nevertheless, the presence of endogenous may alter the assay background making it difficult to standardize. We tested the human serum (positive control) tested in pSBA for active endogenous complement by including a heat inactivated pair alongside the normal serum. As shown in FIG 5 and 6, the test sera have not exhibited any endogenous complement activity. This is evident with the disappearance of titer in the heat treated serum without exogenous complement compared to normal serum with exogenous complement. We anticipate the reappearance of bactericidal activity in the heat inactivated serum if supplemented with exogenous complement. This will be carried out in future studies.

\section{Summary and Conclusion}

The clinical sample obtained from various hospitals \& laboratories were processed, P.aeruginosa was isolated from nutrient agar plate on selective medium. Pseudomonas isolation agar. Heat killed and formalin killed lysate were prepared by an appropriate technique as mentioned in methodology. Serum samples $(n=22)$ collected from various laboratories were screened for pseudomonas specific IgG using direct antibody capture ELISA protocol. Serum samples TS11, TS14, and TS16 had IgG for Ps1 and serum sample TS12 for Ps3. No ELISA sero-reactivity was recorded for Ps2 in any of the test serum samples. A clear distinction among the two different antigen preparations was recorded within the Ps isolates. While serums for Ps1 were more reactive with HK prep, Ps3 was highly reactive to FK suggesting differential exposure of antigens in response to inactivation procedures. Additional experiments as suggested in the results and discussion may provide clarity in this regard.

SBA for the Ps1 and Ps3 looks promising in terms of antibody and complement dependent nature without interference from the endogenous complement or complement lytic activity of the target bacterium. Further optimizations will enable pSBA characterized as a robust serological assay for pseudomonas.

To conclude, this study has demonstrated the feasibility of complement driven in vitro $\mathrm{SBA}$ for $P$. aeruginosa. In vitro serological correlate of protection such as pSBA are important for the development and evaluation of pseudomonas vaccines.

\section{References}

[1] Aldona L. Baltch , Mark C. Hammer, Raymond P. Smith, Tom G. Obrig, Joseph V. Conroy, Monica B. Bishop. Mary A. Egy, and Frieder Lutz. 1985. "Effects of Pseudomonas aeruginosa Cytotoxin on Human Serum and Granulocytes and their Microbicidal, phagocytic, and Chemotactic Functions". Infection and immunity. 48(2): 498-506

[2] Alan R. Hauser and Egon A. Ozer. 2011. "Pseudomonas aeruginosa". Nature Reviews Microbiology.

[3] Alexander J. Laarman, Bart W. Baerdoel, Maartie Ruyker, Job Fernie, Fin J. Milder, Jos A.G. Van Strip and Suzan H.M. Rooijakkers. 2012. "Pseudomonas aeruginosa Alkaline Protease blocks Complement Activation via the Classical and Lectin pathways". J.Immunol. 188:386-393

[4] ANN B. Bjornson and J. Gabriel Michael. 1970. "Biological Activities of RabbitImmunoglobin $\mathrm{M}$ and Immunoglobin $\mathrm{G}$ Antibodies to Pseudomonas aeruginosa". Infection and immunity. 2(4): 453-461

[5] ANN B. Bjornson and J. Gabriel Michael. 1971. "Contribution of Hummoral and Cellular Factors to the Resistance to Experimental Infection by Pseudomonas aeruginosa in Mice I. Interaction Between Immunoglobin, Heat-Labile Serum Factors, and Phagocytic Cells in the Killing of Bacteria". Infection and immunity. 4(4): 462-467

\section{Volume 6 Issue 7, July 2017 www.ijsr.net}




\section{International Journal of Science and Research (IJSR) \\ ISSN (Online): 2319-7064}

Index Copernicus Value (2015): 78.96 | Impact Factor (2015): 6.391

[6] Cassandra Kruczek, Uzma Qaiser, Jane A. ColmerHamood and Abdul N. Hamood. 2014. "Serum influences the expression of Pseudomonasaeruginosa quorum-sensing genes and QS-controlled virulence genes during early and late stages of growth". MicrobioogyOpen. 3(1): 64-79

[7] Charles W. Stratton. 1988. "Serum Bactericidal Test". Clinical Microbiology Reviews. 1(1): 19-26

[8] Dr. Colin Tidy. 2014. "Pseudomonads". Patient. 24:1616

[9] Colleen T. O'Loughin, Laura C. Miller, Albert Siryaporn, Knut Drescher, Martin F. Semmelhack and Bonnie L. Bassler. 2013. "A quorum-sensing inhibitor blocks Pseudomonas aeruginosa virulence and biofilm formation". PNAS. 110(44): 17981-17986

[10] Giuseppantonio Maisetta, Giovanna Batoni, Semith Esin, Walter Florio, Daria Bottai, Flavia Favilli and Mario Campa. 2006. "In Vitro Bactericidal Activity of Human $\beta$-Defensin 3 against Multidrug-Resistant Nosocomial Strains". Antimicrobial Agents and Chemotheraphy. 50(2):806

[11] A. Glynn and Celia M. Miline. 1967. “A Kinetic Study of the Bacteriolytic and Bactericidal Action of Human Serum". Immunology. 12:639

[12] Gregory P. Priebe, and Joanna B. Goldberg. 2014."Vaccines for Pseudomonas aeruginosa: A long and winding road." Expert Rev Vaccines. 13(4): 507519

[13] R. M. Guttman and B. A. Waisbren. 1975. "Bacterial Blocking Activity of SpecificIgG in Chronic Pseudomonas aeruginosa Infection". Clin. Exp. Immunol.19:121-130

[14] Hossein Fazeli, Reza Akbari, Sharareh Moghim, Tahmineh Narimani, Mohammad Reza Arabestani, and Ali Reza Ghoddousi. 2012. "Pseudomonas aeruginosa infections in patients, hospital means, and personnel's specimens". J Res Med Sci. 17(4):332-337

[15] Jamileh Nowroozi, Abbas Akhavan Sepahi, Afrooz Rashnonejad. 2012. "Pyocyanine Biosynthetic Genes in Clinical and Environmental Isolates of Pseudomonas aeruginosa and Detection of Pyocyanine's Antimicrobial Effects with or without Colloidal Silver Nanoparticles". Cell Journal. 14(1):7-18

[16] Kanokporn Chaianunporn, Sonvanee Tanuchit, Sutthiwan Thammawat, Thotsapol Chaiaunporn. 2016. "Antibiotic Resistance of Environmental Isolates of Pseudomonas aeruginosain Mahasarakham province and Nong BUA Lamphu province". J.Sci.Technol MSU. 35(2)

[17] Dr. Lowell S. Young. 1972." Human Immunity to Pseudomonasaeruginosa. I. In-vitro Interaction of bacteria, Polymorphonuclear leukocytes, and Serum Factors". J.infect Dis.126(3): 257-276

[18] Mary Jane Thomassen and Catherine A. Demko. 1981. "Serum Bactericidal Effect on Pseudomonas aeruginosa Isolates from Cystic Fibrosis Patients". Infection and immunity. 33(2): 512-518

[19] Maurice Landy, J. Gabriel Michael, and James L. Whitby. 1961. "Bactericidal Method for the Measurement in Normal Serum of Antibody to Gramnegative bacteria". J. Bacteriol.83: 631-640

[20] Meenu Mishra, Adam Ressler, Larry S. Schlesinger, Daniel J. Wozniak. 2015. "Identification of OprF as a
Complement Component C3 Binding Acceptor Molecule on the Surface of Pseudomonasaeruginosa". Infect.Immun.83: 3000-3014

[21] Meenu Mishra, Matthew S. Byrd, Susan Sergeant, Abul K. Azad, Matthew R. Parsek, Linda McPhail, Larry S. Schlesinger, Daniel J. Wozniak. 2012. "Pseudomonas aeruginosaPsl polysaccharide reduces neutrophilphagocytosis and the oxidative response by limiting complement-mediated opsonization". Cellular Microbiology.14 (1): 95-106

[22] Nadine Hoffmann, Baoleri Lee, Morten Hentzer, Thomas Bovbjerg Rasmussen, Zhijun Song, Helle Krogh Johansen, Michael Givskov, and Niels Hoiby. 2007. "Azithromycin Blocks Quorum Sensinng and Alginate Polymer Formation and Increases the Sensitivity to Serum and Stationary-Growth-Phase Killing of Pseudomonas aeruginosa and Attenuates Chronic P. aeruginosa Lung Infection in Cftr Mice". Antimicrobial Agents And Chemotherapy.51(10): $3677-$ 3687

[23] Nathalie J. Schmidt, Pinkie S. Gee, Juanita Dennis, and Edwin H. Lennette. 1969. "Enzymes Produced by a Pseudomonas Species Which Inactivate Inhibitors of Certain Viral Hemagglutinins." Applied Microbiology. 18(3): 500-508

[24] Neal L. Schiller. 1988. "Characterization of the Susceptibility of Pseudomonas aeruginosa to Complement-Mediated Killing: Role of Antibodies to the Rough Lipopolysaccharide on Serum-Sensitive Strains." Infection And Immunity. 56(3): 632-639

[25] Neal L. Schiller, Michael J. Alazard and Robert S. Borowski. 1984. "Serum Sensitivity of a Pseudomonas aeruginosaMucoid Strain." Infection and Immunity. 45(3): 748-755

[26] Ogunnusi Tolulope Adeola and Adeyinka Rilwan Babatunde. 2016. "Studies of Antibiotics Resistance of Pseudomonas aeruginosa from Clinical and Environmental (Water and Soil) Samples." EJPMR. 3(7): 59-62

[27] Pauline B. Van de Weert-van Leeuwen, Marit A. Van Meegen, Jennifer J. Speirs, D.J. Pals, Suzan H. M. Rooijakkers, Cornelis K. Van derEnt, Suzanne W. J. Terheggen-Lagro, Hubertus G. M. Arets, and Jeffrey M. Beekman. 2013. "Optimal ComplementMediated Phagocytosis of Pseudomonas aeruginosaby Monocytes Is Cystic Fibrosis Transmembrane Conductance Regulator-Dependent." Am J Respir Cell Mol Biol. 49(3): 463-470

[28] Peter Ames, Denise DesJardins and Gerald B. Pier. 1985. "Opsonophagocytic Killing Activity of Rabbit Antibody to Pseudomonas aeruginosa Mucoid Exopolysaccharide." Infection and Immunity. 49(2): 281-285

[29] Peter W. Taylor. 1983. "Bactericidal and Bacteriolytic Activity of Serum against Gram-Negative Bacteria." Microbiological Reviews. 47(1): 46-83

[30] Pier GB, Thomas D, Small G, Siadak A, Zweerink H. 1989."In vitro and in vivo activity of polyclonal and monoclonal human immunoglobulins G, M, and A against Pseudomonas aeruginosalipopolysaccharide." Infect Immun.57(1): 174-9

[31] Pier GB, Takeda S, Grout M, Markham RB. 1993. "Immune complexes from immunized mice and 


\section{International Journal of Science and Research (IJSR) \\ ISSN (Online): 2319-7064}

Index Copernicus Value (2015): 78.96 | Impact Factor (2015): 6.391

infected cystic fibrosis patients mediate murine and human $\mathrm{T}$ cell killing of hybridomas producing protective, opsonic antibody to Pseudomonas aeruginosa." J Clin Invest. Mar; 91(3): 1079-87

[32] Priebe GP, Brinig MM, Hatano K, Grout M, Coleman FT, Pier GB, Goldberg JB. 2002"Construction and characterization of a live, attenuated aroA deletion mutant of Pseudomonas aeruginosa as a candidate intranasal vaccine." Infect Immun. 70(3): 1507-17

[33] Robert J. Roantree and Lowell A. Rantz. 1959. “A Study of Relationship of the Normal Bactericidal Activity of Human Serum to Bacterial Infection."

[34] D. Rowley. 1968. "Sensitivity of Rough Gram-negative Bacteria to the Bactericidal Action of Serum." Journal of Bacteriology. 95(5): 1647-1650

[35] D. Rowley and A. C. Wardlaw. 1958. "Lysis of GramNegative Bacteria by Serum." J. gen. Microbiol. 18: 529-533

[36] Shaan L. Gellatly and Robert E.W. Hancock. 2013. "Pseudomonas aeruginosa: new insights into pathogenesis and host defenses." Pathogens and Disease. 67: 159-173

[37] Sidney Gaines and Maurice Landy. 1954. "Prevalence of Antibody to Pseudomonas in Normal Human Sera."

[38] Stacey L. Mueller-Ortiz, Scott M. Drouin, and Rick A. Wetsel. 2004. "The Alternative Activation Pathway and Complement Component C3 Are Critical for a Protective Immune Response against Pseudomonas aeruginosa in a Murine Model of Pneumonia." Infection and Immunity. 72(5): 2899-2906

[39] Tiffany R. Keepers, Marcela Gomez, Chris Celeri, Wright W. Nichols, Kevin M. Krause. 2014. "Bactericidal Activity, Absence of Serum Effect, and Time-Kill Kinetics of Ceftazidime-Avibactum against $\beta$-Lactamase-Producing

Enterobacteriaceaeand Pseudomonas aeruginosa." Antimicrobial Agents and Chemotherapy. 58(9): 5279-5305

[40] Tim O. Hirche, Rymm Benabid, Gaetan Deslee, Sophie Gangloff, Samuel Achilefu, Moncef Guenouou, Francois Lebargy, Robert E. Hancock and Azzaq Belaaouaj. 2008. "NeutrophilElastase Mediates Innate Host Protection against Pseudomonas aeruginosa." J. Immunology.181: 4945-4954

[41] Vishnu Prasad Shenoy, Mamatha Ballal, P G Shivananda and Indira Bairy. 2012. "Honey as an Antimicrobial Agent AgainstPseudomonas aeruginosa isolated from Infected wounds." J. Glob. Infect. Dis. 4(2): 102-105

[42] Wu W, Huang J, Duan B, Traficante DC, Hong H, Risech M, Lory S, Priebe GP. 2012."Th17stimulating protein vaccines confer protection against Pseudomonas aeruginosa pneumonia."Am J RespirCrit Care Med. 186(5): 420-7

[43] Yoshifumi Imamura, Yasuhito Higashiyama, Kazunori Tomono, Koichi Izumikawa, Katsunori Yanagihara, Hideaki Ohno, Yoshitsugu Miyazaki, Yoichi Hirakata, Yohci Mizuta, Jun-ichiKadota, Barbara H. Iglewski, and Shigeru Kohno. 2005. "Azithromycin Exhibits Bactericidal Effects on Pseudomonas aeruginosathrough Interaction with the
Outer Membrane." Antimicrobial Agents and Chemotherapy. 49(4): 1377-1380

[44] Young LS, Meyer RD, Armstrong D. 1973."Pseudomonas aeruginosa vaccine in cancer patients." Ann Intern Med. 79(4): 518-27

[45] Yuqun Hong and Berhane Ghebrehiwet. 1992. "Effect of Pseudomonas aeruginosaElastase and Alkaline Protease on Serum Complement and Isolated Components C1q and C3." Clinical Immunology and Immunopathology. 62(2): 133-138

\section{Author Profile}

Nandhini D (Post-Graduate student): Pursuing M.Sc in Applied Microbiology from Dr.MGR Janaki College of arts and science for women, University of Madras, Tamilnadu.

Dr. Ramya Anandan (Research Guide) is currently working as Professor in Microbiology Division, Dr.MGR Janaki College of arts and science for women, Tamilnadu. 